\title{
Intestinal mucosal uptake of iron and iron retention in idiopathic haemochromatosis as evidence for a mucosal abnormality
}

\author{
L. W. POWELL, C. B. CAMPBELL, AND ELIZABETH WILSON \\ From the Department of Medicine, University of Queensland, Royal Brisbane Hospital, \\ Brisbane, Australia
}

SUMMARY The process of iron absorption has been studied in 23 patients with idiopathic haemochromatosis, in eight with iron-deficiency anaemia, and in 20 control subjects. The initial uptake of iron by the intestinal mucosa was estimated by administering ${ }^{59} \mathrm{Fe}$-ferric citrate during a standard meal together with a non-absorbable marker, ${ }^{51} \mathrm{Cr}$-chromic chloride. Body iron absorption (iron retained at 14 days) was measured by whole body counting with discriminant analysis to separate the two isotopes. Thus, the fraction of the initial mucosal uptake finally retained in the body was calculated (the mucosal transport index of iron).

In control subjects the mean values for mucosal uptake of iron and body iron absorption were $12.0 \pm \operatorname{SD~} 4.9 \%$ and $3.6 \pm \operatorname{SD~} 2.4 \%$, with a mean mucosal transport index of $0.31 \pm$ SD 0.21 . Mucosal iron uptake and body absorption were both considerably increased in the patients with iron-deficiency anaemia (33.5 \pm 15.6 and $29.8 \pm 17.0 \%$ respectively) and in the eight patients with idiopathic haemochromatosis treated by venesection therapy until the excess iron stores were removed $(27.2 \pm 12.0$ and $26.6 \pm 14.6 \%$ respectively). The mucosal transport index in all these subjects approached 1.0. Eight patients with haemochromatosis were studied before venesection therapy. The mucosal uptake of iron was within the normal range in all (mean $14.0 \pm 2.8 \%$ ) but body iron absorption was increased in five (mean $9.1 \pm$ $4.8 \%$ ). The mean mucosal transport index of iron was significantly increased in this group $(0.62 \pm 0.28 ; \mathrm{P}<0.01)$.

The findings suggest that the increased iron absorption in subjects with idiopathic haemochromatosis results from an abnormality of the intestinal mucosa and not from altered intraluminal factors. However, whether the aberrant mucosal cell function is a primary defect in the cell or an acquired change, dependent on humoral or corporeal factors, is unknown.

While there is evidence that the absorption of iron in some patients with idiopathic haemochromatosis is increased, particularly in the early stages of the disease (Charlton and Bothwell, 1966; Williams, Pitcher, Parsonson, and Williams, 1965; Boender and Verloop, 1969; Smith, Godfrey, and Williams, 1969), the underlying mechanism is unknown. Earlier work suggesting an abnormality of intestinal pancreatic secretions (Biggs and Davis, 1963) or gastric juice (Davis, Luke, and Deller, 1966) has not been confirmed (Kavin, Charlton, Jacobs, Green, Torrance, and Received for publication 27 April 1970.
Bothwell, 1967; Smith, Studley, and Williams, 1969; Powell and Wilson, 1969), and it is still uncertain whether the basic metabolic fault lies at the luminal, mucosal, humoral, or corporeal level.

Radioactive labelled non-absorbable markers have simplified the measuring of the absorption of dietary substances such as vitamin $\mathbf{B}_{12}$ (Ganatra, Sundaram, Desai, and Gaitonde, 1965; Campbell and Craswell, 1970) and lipids (Morgan and Hofmann, 1969; Figueroa, Jordan, and Bassett, 1968; Seife and Shils, 1969), and have provided a new approach to the study of the complex handling of iron by the intestinal mucosal cell. Their 
use, coupled with determinations of faecal iron excretion or whole body counting for iron, permits the estimation of the initial uptake of iron by the intestinal mucosa and the proportion of this which is finally retained in the body (Najean and Ardaillou, 1963; Boender, Mulder, Ploem, de Wael, and Verloop, 1967; Flendrig, van Tongeren, Enneking, Hogeweg, and Verhoef, 1968). In an endeavour to determine whether the abnormality of iron absorption in patients with idiopathic haemochromatosis results from a luminal or mucosal abnormality, we have studied the initial intestinal uptake of iron and total body iron absorption (retention) in 20 control subjects, in eight iron-deficient patients, and in 23 patients with idiopathic haemochromatosis.

\section{Patients and Methods}

The 20 controls included eight normal subjects and 12 hospital patients with normal iron metabolism. Their ages ranged from 27 to 75 years (mean 50.5 years). The peripheral blood smear and haemoglobin concentration, the serum iron and total iron-binding capacity (TIBC) were normal in each case, and no patient had a history of recent blood loss. The eight irondeficient patients were anaemic at the time of study; in six the cause was occult blood loss and in two it was dietary deficiency. In 21 of the 23 patients with idiopathic haemochromatosis the diagnosis was made on the basis of the clinical features, an increased percentage saturation of the TIBC, increased chelatable iron (Powell and Thomas, 1967), and a liver biopsy specimen showing the presence of cirrhosis and gross iron deposition. The other two are believed to have 'precirrhotic' idiopathic haemochromatosis (Powell, 1970 ) on the basis of the clinical and biopsy findings, the absence of alcohol consumption, and a positive family history of iron storage disease. Eight patients were untreated at the time of study, while 15 had received treatment by multiple venesections. In eight of these complete removal of the excess iron stores had been achieved, as judged by a sustained fall in haemoglobin concentration, a low serum iron level, and normal or low chelatable iron (Powell and Thomas, 1967). In addition, depletion of iron stores was also confirmed in five patients by repeat liver biopsy.

Mucosal uptake of iron in vivo was measured by a method similar to that described by Boender and Verloop (1969) except that ${ }^{51}$ chromiumlabelled chromic chloride $\left.{ }^{(51} \mathrm{CrCl}_{3}\right)$ was used as the non-absorbable marker. The test dose contained approximately $4 \mu \mathrm{Ci}{ }^{59} \mathrm{Fe}$ as ferric citrate in $0.025 \mathrm{~N}$ hydrochloric acid together with approximately $50 \mu \mathrm{Ci}^{51} \mathrm{CrCl}_{3}$. Adsorption of the ${ }^{51}$ chromium to glassware was minimized by adding $2 \%$ gelatin which was dissolved by heating. The test solution was administered to the fasting subject during a standard breakfast containing $50 \mathrm{~g}$ cornflakes, $150 \mathrm{ml}$ of milk, $50 \mathrm{~g}$ pineapple (containing approximately $5 \mathrm{mg}$ vitamin $\mathrm{C}$ ), $110 \mathrm{~g}$ tinned meat, and one $(30 \mathrm{~g})$ slice of bread. The iron composition of the diet, measured by wet ashing, was $5 \cdot 5-6 \cdot 0 \mathrm{mg}$. The patient had nothing further to eat for at least two hours. Whole body counting was performed four to five hours after the administration of the solution, and again after 14 days, using two, 5-inch thallium-activated sodium iodide detector crystals with the patient moving between them on a motorized couch. All faeces were collected in daily portions for at least two days into tin containers of known weight. The samples were homogenized in water to a total volume of 1 litre and the radioactivity was determined using the same sodium iodide detectors. The $2 \mathrm{ml}$ standard was diluted to 1 litre with water and counted similarly. The two isotopes were separated during both whole body and sample counting by means of discriminant analysis.

The initial mucosal uptake of iron was then calculated as follows:

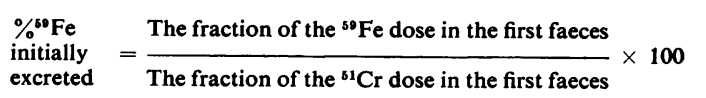
$=\frac{\text { Faecal }{ }^{59} \mathrm{Fe} \text { count rate }}{\text { Standard }{ }^{50} \mathrm{Fe} \text { count rate }} \times \frac{\text { Standard }{ }^{51} \mathrm{Cr} \text { count rate }}{\text { Faecal }{ }^{51} \mathrm{Cr} \text { count rate }} \times 100$.

The initial mucosal uptake of ${ }^{59} \mathrm{Fe}(\%)$

$=100$ - percentage initially excreted.

The faecal specimen used was the first one to contain significant radioactivity. Subjects with constipation were excluded from the study.

Body iron absorption was measured in most subjects by whole body counting as described above. However, in some cases this was also measured by a modification of the double isotope technique described by Saylor and Finch (1953). The results by these two methods were in close agreement (Campbell and Powell, 1970). The ultimate iron retention was also expressed as a fraction of the initial mucosal uptake (retention/uptake) to give an estimate of the fraction of the iron initially taken up by the mucosa which was transported into the plasma ('mucosal transport index of iron').

\section{Results}

CONTROL SUBJECTS AND PATIENTS WITH IRON DEFICIENCY

The mean values for initial mucosal uptake of iron and total body iron absorption in the control subjects were $12.0 \pm$ SD $4.9 \%$ and $3.6 \pm$ SD $2.4 \%$ respectively. The mean mucosal transport index was $0.31 \pm 0 \cdot 21$. Total recovery of ${ }^{51} \mathrm{Cr}$ activity in the faeces was between $94.1 \%$ and 
$102.3 \%$ in eight control subjects, and whole body counting for ${ }^{51} \mathrm{Cr}$ activity confirmed that no chromium remained in the subjects after the first five days. In patients with iron deficiency both intestinal uptake and body iron absorption were markedly elevated $(33.5 \pm 15.6 \%$ and $29.8 \pm$ $17.0 \%$ respectively). Thus, most of the iron taken up by the mucosa was retained in the body (mean mucosal transport index $0.85 \pm 0 \cdot 14$ ). Again the marker was completely recovered in patients in this group, and virtually all the ${ }^{51} \mathrm{Cr}$ activity was recovered within five days.

\section{PATIENTS WITH IDIOPATHIC}

HAEMOCHROMATOSIS

In the subjects with idiopathic haemochromatosis studied before the start of venesection therapy the initial mucosal uptake of iron was within the normal range in all (mean $14.0 \pm 2.8 \%$ ) but body iron absorption was increased in five (mean 9.1 $\pm 4.8 \%$ ). The mean mucosal transport index of iron was also significantly increased $(0 \cdot 62 \pm 0 \cdot 28$; $\mathrm{t}=2.99, \mathrm{P}<0.01)$. Seven patients were studied during venesection treatment. The mean values for both initial mucosal uptake and body absorption of iron in this group were increased $(30 \cdot 1 \pm$ $12.3 \%$ and $14.6 \pm 10.1 \%$ respectively) but body iron retention and mucosal transport indices were generally lower than in the patients studied after completion of treatment (see Figure). The two patients in whom absorption was normal had stopped treatment of their own accord approximately four years before this study. In another patient, although the initial mucosal uptake was normal $(16.3 \%)$, iron absorption was increased $(14.6 \%)$. The mucosal uptake of iron and body iron absorption in the eight patients studied after venesection therapy were similar to those in patients with iron deficiency (mean values $27.2 \pm$ $12.0 \%$ for initial uptake, $26.6 \pm 14.6 \%$ for body retention, and $0.77 \pm 0.36$ for the mucosal transport index). The faecal recovery of ${ }^{51} \mathrm{Cr}$ in seven patients with haemochromatosis was again virtually complete (range $95.7 \%$ to $104.8 \%$ ) within five days.

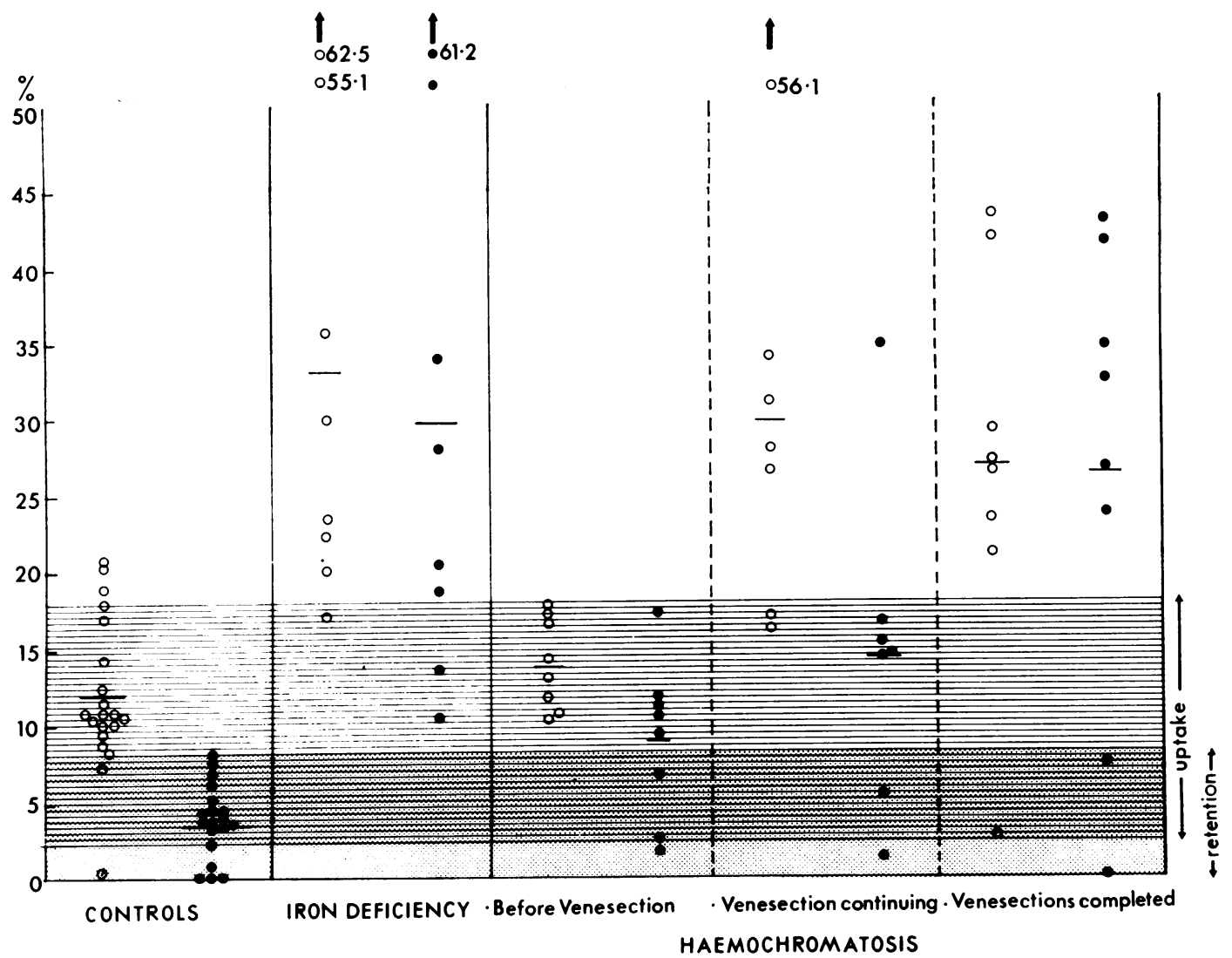

Fig. Initial mucosal uptake of iron (open circles) and body iron absorption retention ie (closed circles), in control subjects, patients with iron-deficiency anaemia, and patients with idlopathic haemochromatosis. The normal ranges for mucosal uptake and body retention are indicated by the shaded areas. 


\section{W. Powell, C. B. Campbell, and Elizabeth Wilson}

\section{Discussion}

Techniques using radioactive labelled nonabsorbable markers to study the absorption of labelled dietary substances depend upon the uniform distribution of the two radioactive isotopes in the intestinal contents. Seife and Shils (1969), using ${ }^{131} \mathrm{BaSO}_{4}$ to study the absorption of ${ }^{131}$-iodine triolein, found that the distribution of the two isotopes was the same in spot samples of faeces and homogenized stools, and that the results of the double isotope studies were in excellent agreement with those of classic fat balance procedures. Similar conclusions were reached by Campbell and Craswell (1970) using ${ }^{51} \mathrm{Cr}$-chromic chloride and ${ }^{58} \mathrm{Co}$-cyanocobalamine, and by

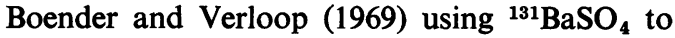
study intestinal mucosal iron uptake and absorption of labelled iron. In the present study ${ }^{51} \mathrm{Cr}$ chromic chloride bound to gelatin was found to be a reliable non-absorbable marker being completely excreted in the faeces within five days.

The work of Conrad and Crosby (1963) in rats and of Boender and Verloop (1969) in man suggested that under normal circumstances a proportion of the dietary iron taken up from the intestinal lumen is temporarily stored in the mucosal epithelial cells and later excreted in the faeces with the normal exfoliation of the intestinal epithelium. Our results confirm these findings and suggest that, in normal subjects, about one-third of the inorganic iron taken up from the lumen is retained. In this study the test solution was given during the course of a meal of standard iron content, resulting in lower values for mucosal uptake and body absorption of iron than those of Boender and Verloop, who administered the labelled iron to fasting subjects. However, the proportion of iron retained by normal control subjects was very similar in the two studies. Results in patients with iron deficiency were also in close agreement in that most of the iron taken up by the mucosa was retained.

The results in patients with untreated haemochromatosis in the present study are of particular interest. Whereas body absorption of iron was increased in five patients, the values for mucosal uptake were within the normal range in all. Boender and Verloop (1969) obtained similar results in two untreated patients with idiopathic haemochromatosis. This suggests that the increased iron absorption in subjects with idiopathic haemochromatosis results from an abnormality of the intestinal mucosa and not from altered intraluminal factors. These findings are consistent with the observations that patients with idiopathic haemochromatosis have less ferritin than normal visible on electron microscopy of the epithelial cells of the intestinal villi (Crosby, 1963) and feuer iron-loaded macrophages entering the intestinal lumen (Astaldi, Meardi, and Lisino, 1966; Cattan, Marche, Jori, and Debray, 1967). Patients with haemochromatosis studied after completion of venesection therapy showed the same pattern of mucosal uptake and absorption of iron in the body found in the subjects with iron deficiency. In those patients who were studied during venesection therapy initial mucosal uptake $\stackrel{\overrightarrow{\bar{S}}}{\vec{D}}$ of iron was in the iron-deficient range while body $\overrightarrow{0}$ absorption was moderately increased. Smith et al 흠 (1969) found a similar increase in iron absorption $\frac{\bar{\omega}}{\sigma}$ in patients with haemochromatosis early in the $\frac{\mathbb{D}}{0}$ course of venesection therapy. The considerable increase in mucosal uptake and body iron absorp- क tion in these patients, whose iron stores were still $\vec{\circ}$ grossly increased, indicates the importance of $\overrightarrow{\vec{\omega}}$ increased erythropoiesis and plasma iron turn- ${ }_{\sigma}$ over in the control of iron uptake and absorption.

Knowledge of the role of the mucosal cell in iron absorption is still meagre, although recently $\overrightarrow{0}$ published work has provided evidence suggesting that mucosal enzymes are involved (Weintraub, N Weinstein, Huser, and Rafal, 1968; Manis, 1969). 으 If the metabolic fault in subjects with idiopathic haemochromatosis is at the mucosal level, it is $\infty$ possible that it results either from an inherited $\frac{\mathbb{D}}{0}$ defect in a mucosal cell enzyme system controlling iron absorption, or from an acquired change in the cell dependent on other factors, either humoral or corporeal. Clearly, further detailed studies are $\vec{\omega}$ required to determine the role, if any, of enzymes in the control of iron uptake and transport by the intestinal mucosa and their relevance to idiopathic haemochromatosis.

We wish to thank those physicians at the Royal Brisbane Hospital who have allowed us to study patients under their care, and Dr I. Buttfield for invaluable assistance with the radioactive isotope counting.

\section{References}

Astaldi, G., Meardi, G., and Lisino, T. (1966). The iron content of jejunal mucosa obtained by Crosby's biopsy in haemochromatosis and hemosiderosis. Blood, 28, 70-82.

Biggs, J. C., and Davis, A. E. (1963). Relationship of diminished pancreatic secretion to haemochromatosis. Lancet, 2, 814. $\mathrm{N}$

Boender, C. A., Mulder, E., Ploem, J. E., de Wael, J., and $\sigma$ Verloop, M. C. (1967). Iron absorption and retention in $\mathrm{N}$ man. Nature (Lond.), 213, 1236-1237.

Boender, C. A., and Verloop, M. C. (1969). Iron absorption, iron N loss and iron retention in man: studies after oral administration of a tracer dose of ${ }^{50} \mathrm{FeSO}_{4}$ and ${ }^{131} \mathrm{BaSO}_{4} . C$ Brit. J. Haemat., 17, 45-58.

Campbell, C. B., and Craswell, P. W. (1970). A double isotope method to measure vitamin B12 absorption. Aust. Ann. Med., 19, $42-46$

Campbell, C. B., and Powell, L. W. (1970). The use of Triton $\mathrm{X}-100$ scintillant in a simple method for the simultaneous assay of ${ }^{55} \mathrm{Fe}$ and ${ }^{\circ} \mathrm{Fe}$ by liquid scintillation counting. J. clin. Path., 23, 304-308.

Cattan, D., Marche, C., Jori, G. P., and Debray, C. (1967). Le stock martial des villosités duodéno-jéjunales: l'absorption martiale vue par l'histologie. Nouv. Rev. franc. Hémat., 7, 259-270.

Charlton, R. W., and Bothwell, T. H. (1966). Hemochromatosis: Dietary and genetic aspects. Progr. Hematol., 5, 298-323.

Courad, M. E. Jr., and Crosby, W. H. (1963). Intestinal mucosal mechanisms controlling iron absorption. Blood, 22, 406 415. 
Crosby, W. H. (1963). The control of iron balance by the intestinal mucosa. Blood, 22, 441-449.

Davis, P. S., Luke, C. G., and Deller, D. J. (1966). Reduction of gastric iron-binding protein in haemochromatosis; a previously unrecognised metabolic defect. Lancet, 2, 14311433.

Figueroa, W. G., Jordan, T., and Bassett, S. H. (1968). Use of barium sulfate as an unabsorbable fecal marker. Amer. $J$. clin. Nutr., 21, 1239-1245.

Flendrig, J. A., van Tongeren, J. H. M., Enneking, J. H. J., Hogeweg, I. B., and Verhoef, C. W. (1968). Het meten van ijzerresorptie en ijzerrententie met een totale-lichaamsteller, in het bijzonder bij patienten met idopathische hemochromatose. Ned. T. Geneesk., 112, 923-924.

Ganatra, R. D., Sundaram, K., Desai, K. B., and Gaitonde, B. B. (1965). Determination of absorption of vitamin B12 by a double isotope tracer technique. J. nucl. Med., 6, 459-464.

Kavin, H., Charlton, R. W., Jacobs, P., Green, R., Torrance, J. D., and Bothwell, T. H. (1967). Effect of the exocrine pancreatic secretions on iron absorption. Gut, 8, 556-564.

Manis, J. (1969). Ferrous iron oxidation by intestinal mucosal homogenates and its possible relation to iron absorption. (Abstr.) J. clin. Invest., 48, 55a.

Morgan, R. G. H., and Hofmann, A. F. (1969). A non-absorbable lipid marker, ${ }^{3} \mathrm{H}$ glyceryl triether. Clin. Res., 17, 308.

Najean, Y., and Ardaillou, N. (1963). Technique de dosage de l'absorption digestive du fer à l'aide d'un indicateur inerte radio-actif. Nouv. Rev. franç. Hémat., 3, 82-83.
Powell, L. W. (1970). Changing concepts in haemochromatosis. Postgrad. med. J., 46, 200-209.

Powell, L. W., and Thomas, M. J. (1967). Use of diethylenetriamine penta-acetic acid (D.T.P.A.) in the clinical assessment of total body iron stores. J. clin. Path., 20, 896-904.

Powell, L. W., and Wilson, Elizabeth (1969). In-vivo intestinal mucosal uptake of iron, body iron absorption and gastric iron binding in haemochromatosis. Proc. Aust. Soc, med. Res., 2, 284-286.

Saylor, L., and Finch, C. A. (1953). Determination of iron absorption using two isotopes of iron. Amer. J. Phystol. 172, 372-376.

Seife, B., and Shils, M. E. (1969). The estimation of fat absorption in man with the use of double isotopes ${ }^{111} \mathrm{BaSO}$, and 131-iodine triolein. J. Lab. clin. Med., 74, 119-128.

Smith, P. M., Godfrey, B. E., and Williams, R. (1969). Iron absorption in idiopathic haemochromatosis and its measurement using a whole-body counter. Clin. Sci., 37. 519-531.

Smith, P. M., Studley, Frances, and Williams, R. (1969). Postulated gastric factor enhancing iron absorption in haemochromatosis. Brit. J. Haemat., 16, 443-449.

Weintraub, L. R., Weinstein, M. B., Huser, H. J., and Rafal, Sheila (1968). Absorption of hemoglobin iron: the role of a hemesplitting substance in the intestinal mucosa. J. clin. Invest., 47, 531-539.

Williams, R., Pitcher, C. S., Parsonson, A., and Williams, H. S. (1965). Iron absorption in the relatives of patients with idiopathic haemochromatosis. Lancet, 1, 1243-1246. 